Elsevier Editorial System(tm) for

Experimental Thermal and Fluid Science

Manuscript Draft

Manuscript Number: ETFS-D-17-01367R2

Title: HIGHLY STABILIZED PARTIALLY PREMIXED FLAMES OF PROPANE IN A CONCENTRIC FLOW CONICAL NOZZLE BURNER WITH COFLOW

Article Type: SI:10th MCS

Keywords: Partially premixed, Flames, OH-PLIF/SPIV, Stability

Corresponding Author: Dr. Ayman Moustafa Elbaz, Ph.D.

Corresponding Author's Institution: Clean Combustion Research Center

First Author: Ayman Moustafa Elbaz, Ph.D.

Order of Authors: Ayman Moustafa Elbaz, Ph.D.; mohamed Senosy; mohamed

Zayed; William Roberts; Mohy Mansour

Manuscript Region of Origin: EGYPT

Abstract: Partially premixed turbulent flames with non-homogeneous jet of propane were generated in a concentric flow conical nozzle burner in order to investigate the effect of the coflow on the stability and flame structure. The flame stability is first mapped and then high-speed stereoscopic particle image velocimetry, SPIV, plus OH planar laserinduced fluorescence, OH-PLIF, measurements were conducted on a subset of four flames. The jet equivalence ratio $\Phi=2$, Jet exit Reynolds number $\operatorname{Re}$ $=10,000$, and degree of premixing are kept constant for the selected flames, while the coflow velocity, Uc, is progressively changed from 0 to $15 \mathrm{~m} / \mathrm{s}$. The results showed that the flame is stable between two extinction limits of mixture inhomogeneity, and the optimum stability is obtained at certain degree of mixture inhomogeneity. Increasing $\Phi$, increases the span between these two extinction limits, while these limits converge to a single point (corresponding to optimum mixture inhomogeneity) with increasing Re. Regardless the value of $\Phi$, increasing the coflow velocity improves the flame stability. The correlation between recessed distance of the burner tubes and the fluctuation of the mixture fraction, $\square \xi$, shows that at $\square \xi$ around $40 \%$ of the flammability limits leads to optimum flame stability. The time averaged SPIV results show that the coflow induces a big annular recirculation zone surrounds the jet flames. The size and the location of this zone is seen to be sensitive to Uc. However, the instantaneous images show the existence of a small vortical structure close to the shear layer, where the flame resides there in the case of no-coflow. These small vertical structures are seen playing a vital role in the flame structure, and increasing the flame corrugation close to the nozzle exit. Increasing the coflow velocity expands the central jet at the expense of the jet velocity, and drags the flame in the early flame regions towards the recirculation zone, where the flame tracks and matches the spatial locations of low axial velocity fluctuations. At downstream, the flame is seen to conform to the passage of large scale structure. At $\mathrm{UC}_{C}=10$ and $15 \mathrm{~m} / \mathrm{s}$, part of the primary reaction zone is rolled up towards upstream burner nozzle, anchoring the flame to the nozzle tip. This indicates that the 
stabilization of these flames in the presence of the coflow is controlled by the mutual interactions between the central jet and the coflow through the recirculation zone from one side, and the degree of the inhomogeneity of the central jet mixture from the other side. 
This manuscript is intended for the "SI: $10^{\text {th }}$ MCS"

\title{
HIGHLY STABILIZED PARTIALLY PREMIXED FLAMES OF PROPANE IN A CONCENTRIC FLOW CONICAL NOZZLE BURNER WITH COFLOW
}

\author{
A.M. Elbaz ${ }^{\mathrm{a}, \mathrm{b}, *}$, M. S. Senosy , M.F. Zayed ${ }^{\mathrm{d}}$, W.L. Roberts ${ }^{\mathrm{a}}$, and M.S. Mansour ${ }^{\mathrm{d}, \mathrm{e}}$ \\ * ayman.elhagrasy@kaust.edu.sa \\ ${ }^{a}$ Clean Combustion Research Center, King Abdullah University for Science and Technology, Saudi Arabia. \\ ${ }^{\mathrm{b}}$ Mechanical Power Engineering Department - Helwan University, Cairo, Egypt. \\ ${ }^{c}$ National Institute of Laser Enhanced Sciences, Cairo University, Giza, Egypt \\ ${ }^{\mathrm{d}}$ Mechanical Power Engineering Department - Cairo University, Giza, Egypt. . \\ ${ }^{\mathrm{e}}$ Mechanical Engineering Department - The American University in Cairo.
}




\section{Highlights}

- We examined the stability and flame-flow field structures of partially premixed flame with coflow.

- The coflow improves the flame stability relative to the flame without coflow.

- The flow field showed an annular recirculation zone around the central jet with coflow.

- The flame structure is significantly depends on the coflow. 


\title{
HIGHLY STABILIZED PARTIALLY PREMIXED FLAMES OF PROPANE IN A CONCENTRIC FLOW CONICAL NOZZLE BURNER WITH COFLOW
}

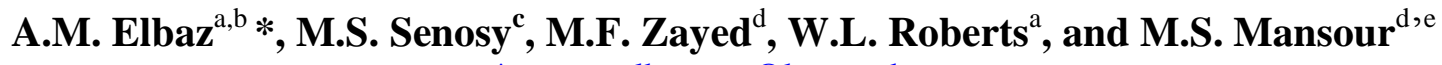 \\ *ayman.elhagrasy@kaust.edu.sa \\ ${ }^{a}$ Clean Combustion Research Center, King Abdullah University for Science and Technology, Saudi Arabia. \\ ${ }^{\mathrm{b}}$ Faculty of Engineering, Mataria, Helwan University, Cairo, Egypt. \\ ${ }^{\mathrm{c}}$ National Institute of Laser Enhanced Sciences, Cairo University, Giza, Egypt. \\ ${ }^{\mathrm{d}}$ Mechanical Power Engineering Department - Cairo University, Giza, Egypt. \\ ${ }^{\mathrm{e}}$ Mechanical Engineering Department - The American University in Cairo.
}

"Special Issue: 10 ${ }^{\text {th }}$ MCS" 


\title{
HIGHLY STABILIZED PARTIALLY PREMIXED FLAMES OF PROPANE IN A CONCENTRIC FLOW CONICAL NOZZLE BURNER WITH COFLOW
}

\author{
A.M. Elbaz ${ }^{\mathrm{a}, \mathrm{b}} *$, M.S. Senosy ${ }^{\mathrm{c}}$, M.F. Zayed ${ }^{\mathrm{d}}$, W.L. Roberts ${ }^{\mathrm{a}}$, and M.S. Mansour ${ }^{\mathrm{d}, \mathrm{e}}$ \\ * ayman.elhagrasy@kaust.edu.sa \\ ${ }^{a}$ Clean Combustion Research Center, King Abdullah University for Science and Technology, Saudi Arabia. \\ ${ }^{\mathrm{b}}$ Faculty of Engineering, Mataria, Helwan University, Cairo, Egypt. \\ ${ }^{\mathrm{c}}$ National Institute of Laser Enhanced Sciences, Cairo University, Giza, Egypt. \\ ${ }^{\mathrm{d}}$ Mechanical Power Engineering Department - Cairo University, Giza, Egypt. \\ ${ }^{\mathrm{e}}$ Mechanical Engineering Department - The American University in Cairo.
}

\begin{abstract}
Partially premixed turbulent flames with non-homogeneous jet of propane were generated in a concentric flow conical nozzle burner in order to investigate the effect of the coflow on the stability and flame structure. The flame stability is first mapped and then high-speed stereoscopic particle image velocimetry, SPIV, plus OH planar laser-induced fluorescence, OH-PLIF, measurements were conducted on a subset of four flames. The jet equivalence ratio $\Phi=2$, Jet exit Reynolds number $\operatorname{Re}=10,000$, and degree of premixing are kept constant for the selected flames, while the coflow velocity, Uc, is progressively changed from 0 to $15 \mathrm{~m} / \mathrm{s}$. The results showed that the flame is stable between two extinction limits of mixture inhomogeneity, and the optimum stability is obtained at certain degree of mixture inhomogeneity. Increasing $\Phi$, increases the span between these two extinction limits, while these limits converge to a single point (corresponding to optimum mixture inhomogeneity) with increasing Re. Regardless the value of $\Phi$, increasing the coflow velocity improves the flame stability. The correlation between recessed distance of the burner tubes and the fluctuation of the mixture fraction, $\Delta \xi$, shows that at $\Delta \xi$ around $40 \%$ of the flammability limits leads to optimum flame stability. The time averaged SPIV results show that the coflow induces a big annular recirculation zone surrounds the jet flames. The size and the location of this zone is seen to be sensitive to Uc. However, the instantaneous images show the existence of a small vortical structure close to the shear layer,
\end{abstract}


where the flame resides there in the case of no-coflow. These small vertical structures are seen playing a vital role in the flame structure, and increasing the flame corrugation close to the nozzle exit. Increasing the coflow velocity expands the central jet at the expense of the jet velocity, and drags the flame in the early flame regions towards the recirculation zone, where the flame tracks and matches the spatial locations of low axial velocity fluctuations. At downstream, the flame is seen to conform to the passage of large scale structure. At $U c=10$ and $15 \mathrm{~m} / \mathrm{s}$, part of the primary reaction zone is rolled up towards upstream burner nozzle, anchoring the flame to the nozzle tip. This indicates that the stabilization of these flames in the presence of the coflow is controlled by the mutual interactions between the central jet and the coflow through the recirculation zone from one side, and the degree of the inhomogeneity of the central jet mixture from the other side.

\section{Key words:}

Partially premixed, Flames, OH-PLIF/SPIV, Stability.

\section{Nomenclature}

D Outer tube inner diameter, $\mathrm{mm}$

L Mixing length or recess distance, $\mathrm{mm}$

r Radial distance, $\mathrm{mm}$

Uc Coflow velocity, $\mathrm{m} / \mathrm{s}$

V Mean axial velocity, $\mathrm{m} / \mathrm{s}$

$\mathrm{V}_{\text {cen }} \quad$ Mean axial centerline velocity, $\mathrm{m} / \mathrm{s}$

$\mathrm{V}_{\text {jet }} \quad$ Axial jet velocity, $\mathrm{m} / \mathrm{s}$

$\mathrm{Z} \quad$ Axial distance, $\mathrm{mm}$

$\xi \quad$ Mixture fraction

$\Phi \quad$ Jet equivalence ratio 


\section{Introduction}

Investigation of turbulent partially premixed flames with inhomogeneous mixing field has attracted many research groups during the last few decades (see Masri [1] for detailed review) because these flames represent the turbulent combustion mode in many practical combustion systems. This mode is affected by the degree of partial premixing and thus it covers a wide range of combustion regimes between the non-premixed and fully premixed modes of combustion [2]. The methods of generating turbulent partially premixed flames with well-defined inhomogeneous mixing field structure are very limited in the literature. Among those methods are the reverse flow reactor with multi side fuel jets into air jet [3], and the concentric flow burner [4-6]. The advantage of the latter burner design is the simple control mechanism providing a wide range of partial premixing and the well-defined boundary conditions. Recently, Thong et al. [7-9] have investigated the structure of the mixing field using multilateral fuel jets in a turbulent jet flow, similar to Mansour et al. [3]. Their flames are more stable than those generated in the concentric flow burners. However the mixing control mechanism is not simple to cover wide range of partially premixed flames like the concentric burner. Counter flow burners $[10,11]$ were used earlier to generate partially premixed flames but the mixing field in those flames does not represent the inhomogeneous structure of practical combustion systems.

The published data of turbulent partially premixed flames with inhomogeneous mixing field are not sufficient to fully describe the flame structure within the expected different regimes of partially premixed flames. Previous experimental investigations covered the stability of partially premixed flames as compared to non-premixed and fully premixed flames [6, 12-16]. The data showed that partially premixed flames are more stable than both non-premixed and fully 
premixed flames [12]. Our research group covered several turbulent partially premixed methane flames with inhomogeneous mixing field in a concentric flow conical nozzle burner, CFCN, where different flame aspects were investigated, including the flow field structure [15, 17], the flame structure [16, 18-20] and, recently, the mixing field structure [21]. Masri and his research group have also investigated turbulent partially premixed flames of methane and natural gas in a piloted concentric flow burner $[1,6,13,22]$. The stability characteristics of both burners are quite similar although the stabilization mechanism is different. This indicates that the stability depends on the nature and level of inhomogeneity of the jet at the nozzle exit. The conical nozzle in the first burner [4] and the pilot in the second burner [6] improve the range of stability but do not change the trend of the stability. Mansour et al. [21] have recently provided a detailed investigation of the effect of the mixing field characteristics on the stability and flame structure. They concluded that the range of fluctuations of mixture fraction has a significant effect on the flame stability where the most stabilized flames are created for a range of fluctuations within the flammability limits. Our previous investigations addressed the stability characteristics, flow field and flame structure of turbulent partially premixed flames of methane with inhomogeneous mixing field at the nozzle exit $[12,15,16,21]$. The species distribution, temperature field, and stability of LPG partial premixed flames stabilized in the CFCN burner have been investigated by Elbaz [23] However, more detailed studies are required in different flames for different fuels in order to cover a wide range of partially premixed flames.

Accordingly, the aim of this work is to further study turbulent partially premixed propane flames created in the CFCN burner with air coflow. The effects of the jet mean equivalence, $\Phi$ and the air coflow velocity, Uc, on the flame stability are first investigated. After characterization of the flame stability, the flow field and flame structure are studied in details 
using high speed measurements of the flow field and $\mathrm{OH}$ field, seeking understanding of the physical effects of the flame dynamic/flow fields interaction on the flame stability in the presence of air coflow. These measurements are conducted on four flames at jet Reynolds numbers, Re, of 10000, $\Phi=2$, and certain level of mixture inhomogeneity, but with various Uc between 0 and $15 \mathrm{~m} / \mathrm{sec}$.

\section{Burner and Experimental Setup}

2.1.The concentric flow conical nozzle burner (CFCN) with coflow

A detailed description of the CFCN burner is published in [15, 21]. The burner, is shown in Fig. 1a, consists of two concentric tubes of $4 \mathrm{~mm}$ and $9.7 \mathrm{~mm}$ inner diameters with a lip thickness of $1 \mathrm{~mm}$ and $1.5 \mathrm{~mm}$, respectively. The air flows through the inner tube, while propane passes through the outer tube. The inner tube can be recessed within the outer fuel tube, creating variable level of fuel-air mixing at the exit of the outer tube. The level of inhomogeneity is controlled by the recess distance L. Fully premixed mixture conditions are obtained at sufficiently large $\mathrm{L} / \mathrm{D}$, while fully non-premixed conditions are achieved at $\mathrm{L} / \mathrm{D}=0$, where $\mathrm{D}$ is the inner diameter of the outer tube. A divergent conical nozzle with a cone angle of $52^{\circ}$ is attached at the exit of the outer tube in order to improve the flame stability $[12,23]$. The exit diameter of the conical nozzle is $73 \mathrm{~mm}$ with a nozzle height of $65 \mathrm{~mm}$. To investigate the effect of coflow velocity on the flame stability and flame structure, the burner is placed in a vertical wind tunnel of a circular cross section of $250 \mathrm{~mm}$ diameter. The exit of the conical nozzle is at the same level of the exit of the coflow tunnel. To ensure a uniform air coflow velocity, three layers of wire meshes were placed at different locations at the top of ceramic honeycomb layer placed inside the coflow wind tunnel.

2.2 PIV and PLIF-OH techniques 
The experimental setup of the simultaneous stereoscopic particle image velocimetry (SPIV), and the two-dimensional OH laser-induced fluorescence (OH-PLIF) techniques is shown in Fig. 1b. Downstream the conical nozzle, the two laser sheets of PIV and OH-PLIF are counter propagated and overlapped to cross the central vertical plan of the burner. The OH-PLIF images are acquired at $10 \mathrm{kHz}$ repetition rate while the SPIV measurements are collected at $500 \mathrm{~Hz}$ repetition rate. Details and specification of SPIV/OH-PLIF techniques can be found in [24, 25]. For the SPIV system, a dual cavity, diode-pumped, solid state Nd: YLF laser (LDY 300) is used. The laser is able to produce a pulse of $3.5 \mathrm{~mJ}$ at $527 \mathrm{~nm}$ wavelength with pulse width of $9 \mathrm{~ns}$. The SPIV images were collected using two high speed CMOS cameras (Lavision, Image Pro $\mathrm{HS} 4 \mathrm{M}, \mathrm{HSS} \%, 1440 \times 1340$ pixels array) located at $\pm 15^{\circ}$ inclination angle to the burner centerline and at the two sides of the OH-PLIF ICCD camera. Each SPIV camera is equipped with $105 \mathrm{~mm}, \mathrm{f} / 4$ objective lens, Nikon UV Micro-Nikkor, and a $527 \mathrm{~nm}$ band bass filter. Titanium dioxide particles of $0.5 \mu \mathrm{m}$ nominal diameter were used for seeding the jet. The SPIV images were processed using Davis 8.1 Lavision software package, where the velocity vectors are calculated by applying spatial cross correlation on the particle images.

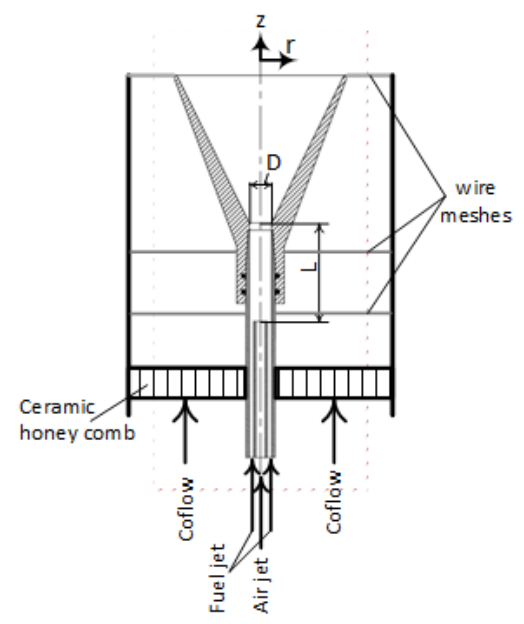

(a)

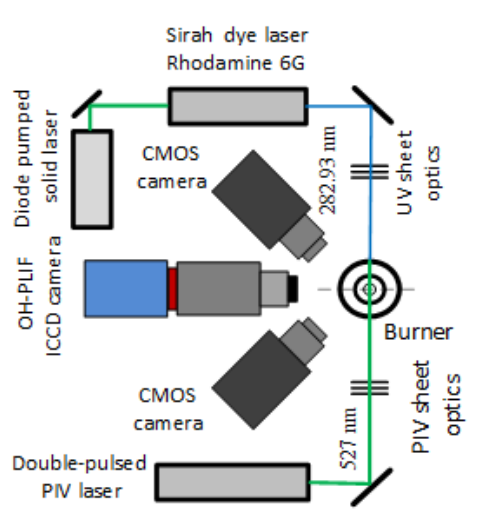

(b) 
Figure 1. (a) Concentric flow conical nozzle burner, CFCN, with air coflow arrangement, (b) Experimental set up.

For the OH-PLIF imaging, the UV beam was generated using a frequency doubled high speed dye laser (Sirah, Cerdo-Dye) pumped by a frequency doubled, diode Solid state INNOSLAB laser (Edgewave, IS16II-E). The dye laser used Rhodamine 6G dye to produce a fundamental beam at $566 \mathrm{~nm}$ wave length, which is then doubled to $283 \mathrm{~nm}$ using BBO doubling crystal. The average laser pulse energy at $10 \mathrm{kHz}$ repetition rate was $2.8 \mathrm{~mJ}$ at $283 \mathrm{~nm}$. The laser sheet of $70 \mathrm{~mm}$ height was focused to approximately $130 \mu \mathrm{m}$ thickness. OH radicals were exited through the $\mathrm{Q}_{1}(6)$ transition of near $283 \mathrm{~nm}(1,0)$ in the band of the $A^{2} \sum 118 \leftarrow X^{2} \prod(1,0) \mathrm{OH}$ system. The OH-PLIF signal was imaged using ICCD camera equipped with Nikkor UV lens $(\mathrm{f} / 4.5, \mathrm{f}=105 \mathrm{~mm})$. Band pass interference filter of a transmission range of $295 \mathrm{~nm}-345 \mathrm{~nm}$, of $>80 \%$ transmission at $310 \mathrm{~nm}$ (custom fabrication-laser components $\mathrm{GmbH}$ ) was used. The effect of laser beam profile on the raw fluorescence images was also corrected using the ensemble average images of 10000 images of the laser sheet passing through a cuvette filled with acetone. In addition, by averaging 5000 frames while blocking the laser, the background and camera noise were corrected.

\section{Results and Discussions}

\subsection{Flame stability and selected flames}

The stability of turbulent partially premixed flames in an earlier version of the CFCN burner was investigated for pure methane [21] and by Elbaz for LPG partial premixed flames [23]. The results indicate that partially premixed flames are more stable than premixed and none premixed flames. Previously in the same burner, Elbaz [23] showed that the use of the conical nozzle improves the flame stability. The range of the mixture fraction fluctuations plays a crucial rule in 
the flame stabilization mechanism. Recently, the effect of the air coflow velocity on the stability of methane partially flames stabilized in CFCN burner was investigated by Elbaz et al. [15]. They [15] found that the existence of the air coflow improves the flame stabilization. However the flame structure, the mixing field, and flame/flow field interaction were not investigated in their work. In this work, three jet equivalence ratios $\Phi$ of $1,1.25$, and 1.5 were selected at $\mathrm{Uc}=5$ and $10 \mathrm{~m} / \mathrm{s}$, for the stability study. The stability curves for these cases are presented in Fig. 2a, where the Reynolds number, Re, at flame extinction is plotted versus the normalized mixing length L/D. The results show that at a certain Re, the flame is stabilized between two limits of the mixing length. This indicates that the flames are stable within a certain range of the mixture inhomogeneity. This also illustrates that partially premixed flames are more stable than both nonpremixed and fully premixed flames. The first extinction limit is at a short mixing length, $(\mathrm{L} / \mathrm{D})_{\min }$, and the second limit is at large mixing length, $(\mathrm{L} / \mathrm{D})_{\max }$.

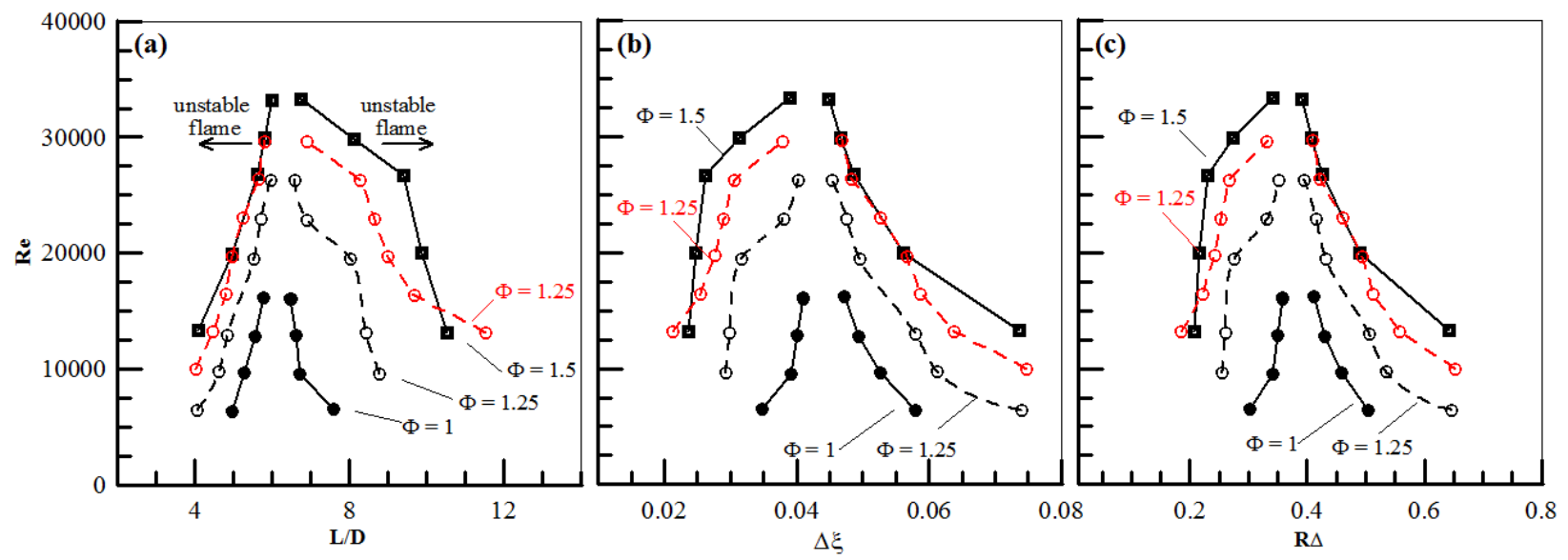

Figure 2. Stability limits of flames at $\Phi=1,1.25$ and 1.5 at $\mathrm{Uc}=5 \mathrm{~m} / \mathrm{s}$ (black lines), and flame stability limits at $\Phi=1.25$ at $\mathrm{Uc}=10 \mathrm{~m} / \mathrm{s}$ (red lines): (a) stability limits against $\mathrm{L} / \mathrm{D}$, (b) stability limits against $\Delta \xi$, and (c) stability limits against $\mathrm{R} \Delta$.

As depicted in Fig. 2a, for a certain equivalence ratio, $\Phi$, increasing Re leads to a gradual decrease of the stability range, thus, leads to a single peak at a certain optimum mixing length, 
L/D. However, increasing the jet equivalence ratio improves the flame stability. On the other hand, increasing the air coflow velocity improves the flame stability as shown in Fig. 2a for the flames at the same equivalence ratio of 1.25 as shown for the flames with $\mathrm{Uc}=5 \mathrm{~m} / \mathrm{s}$ and $10 \mathrm{~m} / \mathrm{s}$. The effect of the air coflow velocity on improving the flame stability is more pronounced at $(\mathrm{L} / \mathrm{D})_{\max }$ limit.

For further investigation, the effect of the mixing length, $\mathrm{L} / \mathrm{D}$, on the mixing field could be deduced using the following correlation [21]:

$$
\Delta \xi=C_{2}\left(\frac{C_{1}-\Phi}{C_{1}+\Phi}\right)\left(\frac{L}{D}\right)^{C_{3}}
$$

Where, $\xi$, is the mixture fraction (conserved scalar), and is defined as the mass percentage of the fuel elements in a gaseous mixture, i.e., $\xi=\sum y_{F i}, y_{F i}$ are the fuel elements' mass fractions [26]. Thus, $\Delta \xi$ is the difference between the maximum and minimum mixture fraction in the mixing field. $\mathrm{C}_{1}$ is constant and a function in the burner dimensions and air-fuel properties. $\mathrm{C}_{2}$, $\mathrm{C}_{3}$ are the correlation derived constants and equal to 0.3845 and -1.1975 , respectively. If the stability map is replotted against $\Delta \xi$ instead of L/D as shown in Fig. 2b, the data show that regardless the coflow velocity, the optimum flame stability is attainable at $\Delta \xi \approx 0.042$ for the all investigated flames. This indicates that the fluctuation in the mixing field is one of the main factors affecting the stability limits of the inhomogeneous mixture. The air coflow velocity alters only the span of the mixture fraction fluctuations and not $\Delta \xi$ of the optimum flame stability. For further analyses, the stability is replotted against $R_{\Delta}$ in Fig. $2 c$, where $R_{\Delta}$ is the ratio between $\Delta \xi$ and the range of the propane flammability limits, defined as the difference between the rich and lean flammability limits [27] at $1 \mathrm{~atm}$ and $298 \mathrm{~K}$. It is interesting that all the stability plots indicates that the most stable flame is at $\mathrm{R}_{\Delta} \approx 0.4$, this means that the optimum mixture inhomogeneity for flame stability is attainable when the fluctuations in the mixture fraction is 
within $40 \%$ of the propane flammability limits. In the following section the mean flow field, instantaneous, and flame structure are investigated and discussed for four propane partial premixed flames using simultaneous stereoscopic SPIV/OH-PLIF measurements. The selected flames are $\mathrm{Fc} 0, \mathrm{Fc} 5, \mathrm{Fc} 10$ and $\mathrm{Fc} 15$ at air coflow velocities of $0,5,10$, and $15 \mathrm{~m} / \mathrm{s}$, respectively. All flames are at $\mathrm{L} / \mathrm{D}=7, \Phi=2$ and $\mathrm{Re}=10000$.

\subsection{The flow field structure}

The ensemble averaged image of 2000 stereo SPIV recordings of flames $\mathrm{Fc} 0, \mathrm{Fc} 5, \mathrm{Fc} 10$, and Fc15 are illustrated in Fig. 3. The measurements covered the region from the nozzle exit up to $150 \mathrm{~mm}$ axial distance, the velocity vectors values in the measurement plane are presented by arrows and overlaid the axial velocity, $\mathrm{V}$, contours. The third velocity component will not be shown for simplicity because it is very small and is less sensitive to the air coflow velocity. To the right of each graph, an enlarged plot shows the streamlines bounded by the white dotted rectangle region indicated in the velocity vector plots. In Fig. 3a, flame Fc0 depicts a typical jet flow features of a partial premixed jet flame without air coflow. Close to the nozzle exit, a higher jet velocity, with relatively low velocity decay within the near axial distances, is depicted. The jet flow does not show the expected radial expansion as illustrated by the radial velocity profiles in Fig. 4a. On the contrary, through the shear layers, the air is entrained from the surrounding, as illustrated by the corresponding streamline plot, and proceeds to a long distance downstream, Fig. 3a. The existence of air coflow creates an annular recirculation zone, RZ, immediately at the conical nozzle exit and surrounds the central flow jet as illustrated in Figs.3b -d. As illustrated by the streamlines plots, large portion of the reversed region (shown by the red lines) located within the exit of the conical nozzle and the rest lies within the coflow duct. This RZ region penetrates deep upstream of the conical nozzle and affects the flow jet pattern. In general, 
increasing the air coflow velocity increases the size of the RZ in both the radial and axial directions. This enhances the mutual interaction between the jet and the air coflow. It is obvious from the flow field of flame Fc5, Fig. 3b, that the early region of the central jet is less sensitive to the air coflow, however a large entrainment is seen from the coflow downstream, see streamlines plot. This is due to the higher central jet momentum relative to the coflow momentum, which leads to the engulfment of the coflow towards the central jet boundaries. By close inspection of the radial velocity profile of flame Fc5 in Fig. 4b relative to flame Fc0 in Fig. 4a, a slight radial expansion of the central jet in flame Fc5 with the coflow is observed. The slight radial expansion of the jet flow in flame Fc5, leads to a slightly faster decay in the centerline velocity relative to the decay in flame $\mathrm{Fc} 0$, as illustrated in Fig. 5, where centerline velocity is normalized by the jet bulk velocity, $\mathrm{V}_{\text {jet }}$.

Increasing the air coflow velocity to $10 \mathrm{~m} / \mathrm{sec}$ leads to a higher reverse velocity that penetrates upstream the conical nozzle and hence high momentum exchange between the coflow and the jet flow, as illustrated in Fig. 3c. This in turn reduces the central jet velocity at the early part of the flame as depicted in Fig. 4c and the centerline velocity shown in Fig. 5. With further increase of Uc to $15 \mathrm{~m} / \mathrm{s}$, the high momentum associated with the coflow jet engulfs the central jet toward the coflow, see the streamlines plot, Fig. 3d, and the coflow has the predominate effect on the central jet. This leads to a steeper decay of the jet centerline velocity and creating an average stagnation point on the central region of the flame nearly at $\mathrm{Z}=80 \mathrm{~mm}$. This is also confirmed by the centerline velocity in Fig 5. It can be observed that the contour of zero axial velocity is shifted towards the central jet with increasing the coflow velocity. This is the reason for the relatively low velocity of the central jet at high Uc as shown in Fig. 4c-d. It is also noted from the centerline velocity in Fig. 5 that the high coflow momentum leads to a recovery of the 
jet velocity at downstream axial distances, due to the gradually convergence of the coflow towards the central flame region beyond where the RZ ends. This explains the gradual change of the flame appearance showed by the flame photos in Fig. 3, where the flame width increases with increasing Uc and eventually the flame is anchored at the tip of the conical nozzle. 

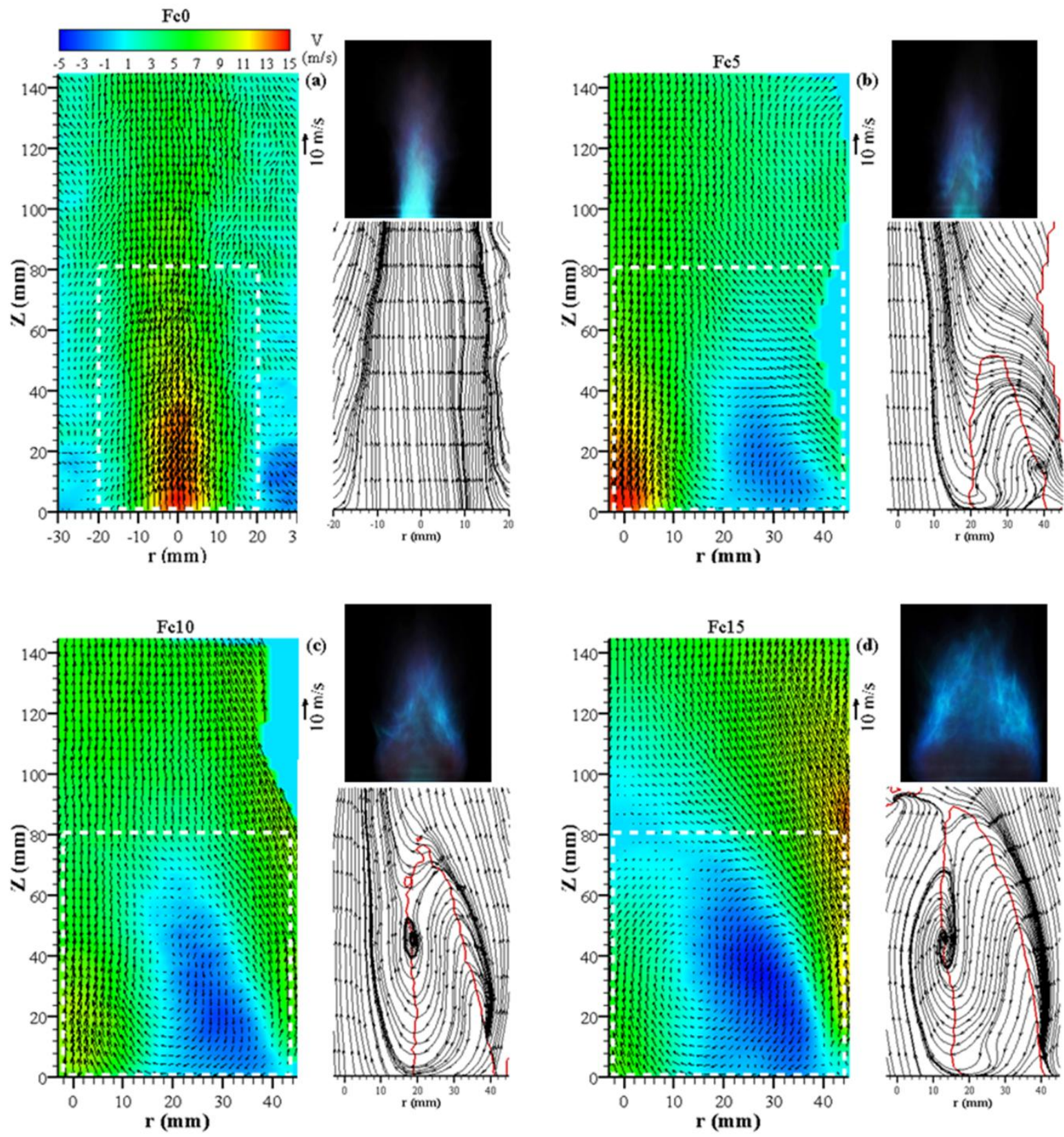

Figure 3. Time average velocity vectors of the four selected flames: (a) flame Fc0, (b) flame Fc5, (c) flame Fc10, and (d) flame Fc15 (alternate velocity vectors has been removed for clarity). To the right of each graph is a direct photo of the flame and a streamline plot for the region bounded by the dotted box, the red line on the streamline plot represents the boundaries of the reversed flow region. 

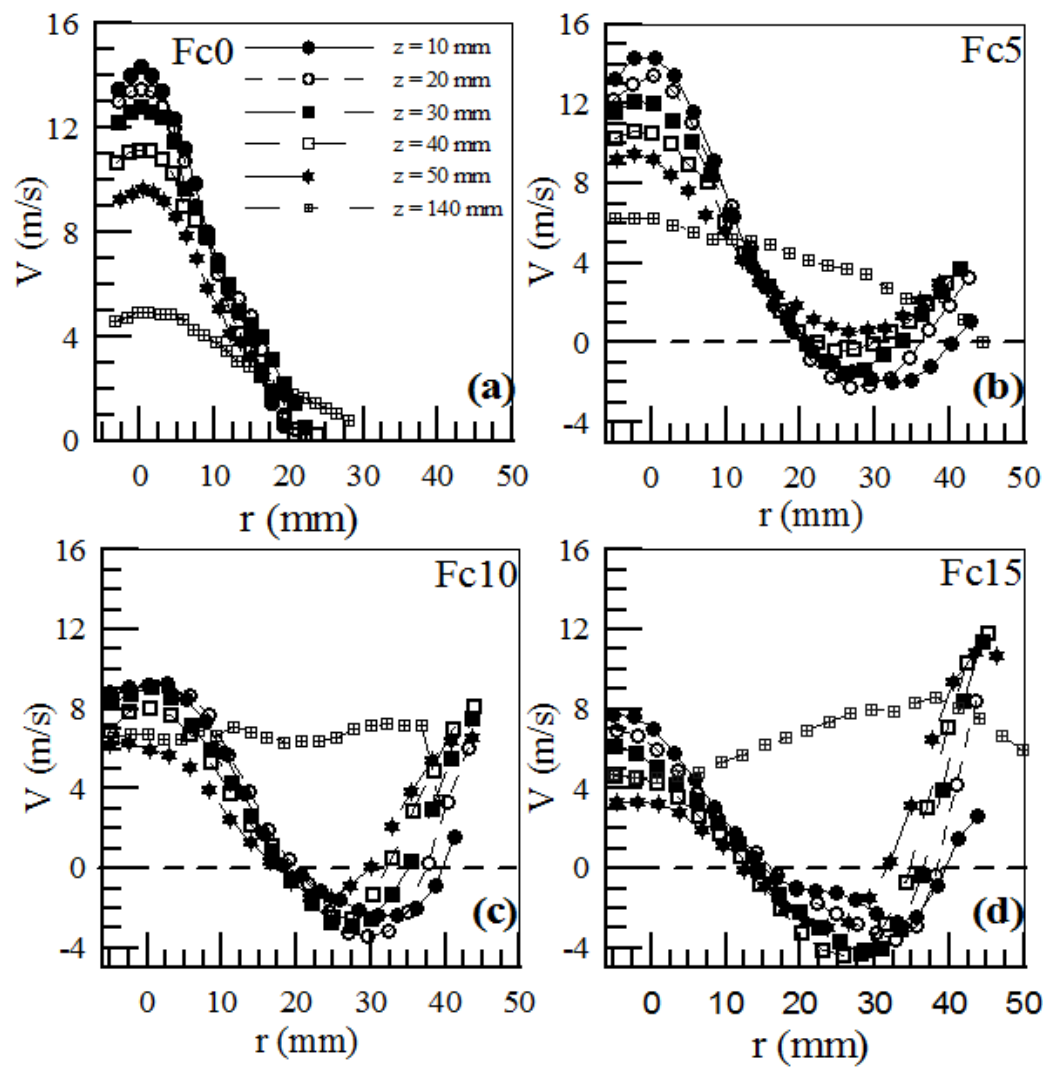

Figure 4. Radial profiles of the mean axial velocity, V, at various axial locations: (a) flame $\mathrm{Fc0}$, (b) flame Fc5, (c) flame Fc10, and (d) flame Fc15.

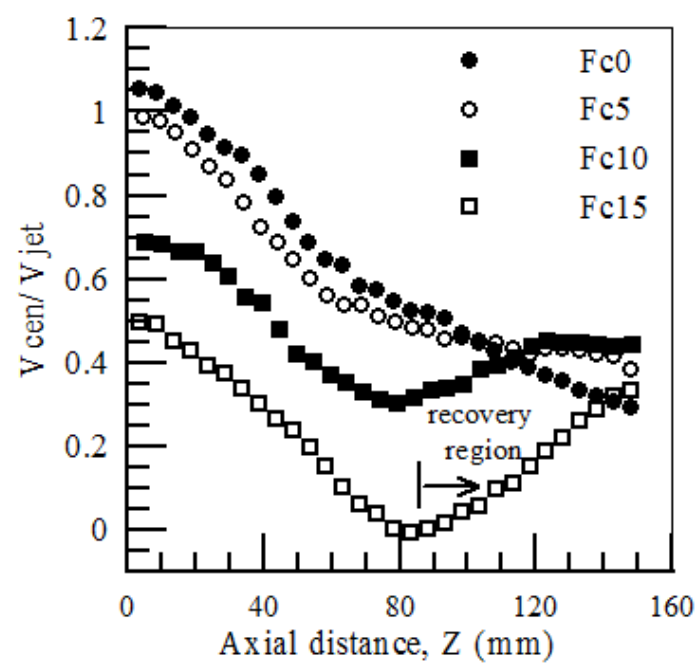

Figure 5. Axial variation of the centerline velocity $\left(\mathrm{V}_{\text {cen }}\right)$ normalized with the jet exit bulk velocity, $\mathrm{V}_{\text {jet }}$, for flames Fc0, Fc5, Fc10, and Fc15. 


\subsection{Flame structure-flame flow field interaction.}

In this section, samples of time-sequences of OH-PLIF images are presented to illustrate the effect of the coflow velocity on the flame structure with time interval of $0.5 \mathrm{~ms}$. Figure 6 shows samples of instantaneous time sequences of the OH-PLIF images measured in the four flames. To explore the interaction between the flow field and the reaction zone, examples of the first and last $\mathrm{OH}$ images presented in Fig. 6 are replotted in Fig. 7 with the corresponding simultaneous velocity vectors.

Figure 6a shows the $\mathrm{OH}$ - time sequences of flame Fc0. Close to the nozzle exit, a thin $\mathrm{OH}$ layer is seen at radial distances of $\pm 10 \mathrm{~mm}$. Further downstream, $\mathrm{Z}>20 \mathrm{~mm}$, a broad zone marked by the OH-PLIF signal are observed. This indicates the formation of vortical structures as a result of the shear stress between the high jet velocity and the surrounding air. One can clearly follow the progress of these vortices and gain information on the structural development of the flame. At the top of the $\mathrm{OH}$ images, the $\mathrm{OH}$ broadening stops and start to converge to the central region where the jet velocity is significantly decreased, as discussed in regards to Fig. 5. Figures $7 \mathrm{a}-7 \mathrm{~b}$ show examples of simultaneous flow/OH fields for the first and last $\mathrm{OH}$ images illustrated in Fig. 6a, for flame Fc0. It is obvious that the instantaneous flow field contains distinctive features that are not presented in the average flow field (Fig. 3a). It shows the existence of vortical structures in the region close to the jet shear layers. These large-scale vortices are formed due to the shear layer instability. These vortices wrinkle and start to roll up the $\mathrm{OH}$ regions as indicated in Figs. $7 \mathrm{a}-7 \mathrm{~b}$ and identified by the red arrows. Consequently the flame surface area increases and correspondingly the reaction rates. Interaction of such nature where a deformation of the $\mathrm{OH}$ layer with vortical structure occurs often in the shear layer and pushes the $\mathrm{OH}$ layer towards the high region axial velocity of the main jet if they succeed in 
weakening the flame by stretch effects. As shown in Figs. 7a-7b, at early right region of the flame, the reaction is formed at the interface of the hot gases coming from the downstream combustion gases by the vortex and the incoming fresh flow of the central jet, where the reaction zone is oriented parallel to the flow field.
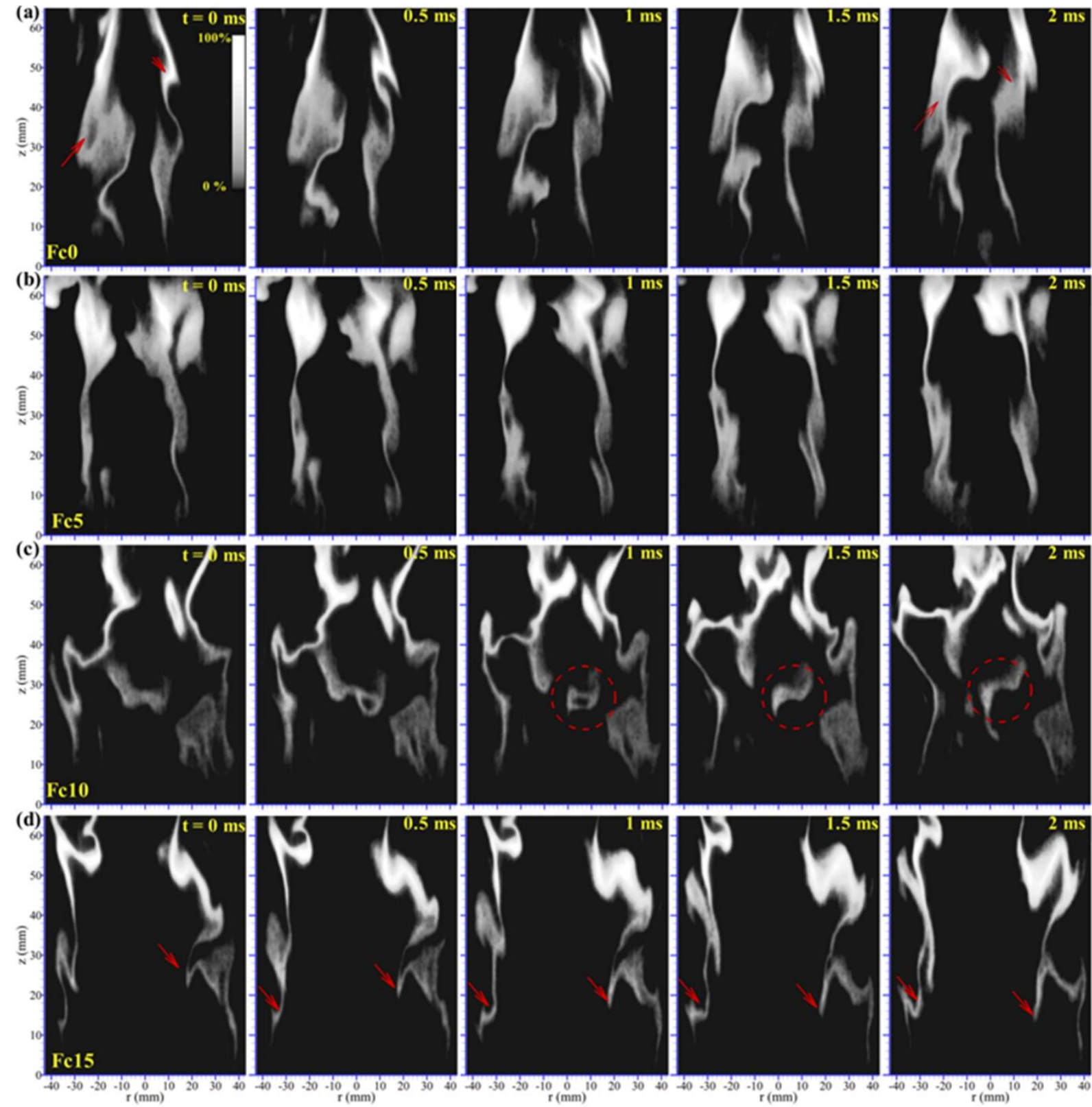

Figure 6. Selected time sequences of OH-PLIF images (gray scale) from left to right with $0.5 \mathrm{~ms}$ time interval between consecutive frames: (a) flame Fc0, (b) flame Fc5, (c) flame Fc10, and (d) flame Fc15. 
The existence of the coflow around the central jet leads to significant changes in the flame structure as illustrated in Figs. 6b-6c. As shown in Fig. 6b for flame Fc5, the OH layer is dragged outward from the central region, and shows a relatively thin two $\mathrm{OH}$ branches for a long distance downstream and start broadening downstream, $\mathrm{z}>45 \mathrm{~mm}$. Recalling the flow field in Fig. $3 \mathrm{~b}$, and radial velocity profiles in Fig. $4 \mathrm{~b}$ of flame Fc5, it can be concluded that the existence of the coflow of $5 \mathrm{~m} / \mathrm{s}$ velocity, creates low velocity gradient at the jet shear layer where the reaction zone resides primarily in the regions of low axial velocity and this is indicated by the superimposed flow/OH fields shown in Figs. 7c-7d, by red ellipses. It is clear that the flame location tracks the large-scale fluctuations in the axial velocity searching for location of low axial velocities at the early flame region. However, the passage of large-scale vertical structures downstream, as indicated by the red arrows in Figs. 7c-7d, is detected. It is also observed that the broadening of the $\mathrm{OH}$ occurs at the end of the reversed region shown in Fig. $3 b$, where the coflow starts to converge toward the central jet.

Further increase of the coflow velocity leads to more outward pushing of the flame, and more corrugation and wrinkling of the $\mathrm{OH}$ layers as shown by the $\mathrm{OH}$ time sequences in Fig. 6c, and Fig. 6d of flames Fc10 and Fc15, respectively. This indicates that the flow field close to the nozzle exit is dominated by the formation and dissipation of vortices. In Fig. 6c, due to the vortices interaction with the flame front, the flame is pulled upstream, close to the conical nozzle side. The high level of wrinkling leads to the formation of flame kernels at the central region of the flame which act as ignition source for the incoming fresh gases, as indicated by the red circles. To the sides of the conical nozzle, the thin wrinkled $\mathrm{OH}$ layer is pushed upstream, where 
it acts as an ignition source of the incoming fresh mixture, and leads to the flame stabilizing close to the nozzle lip and act as a flame holder.
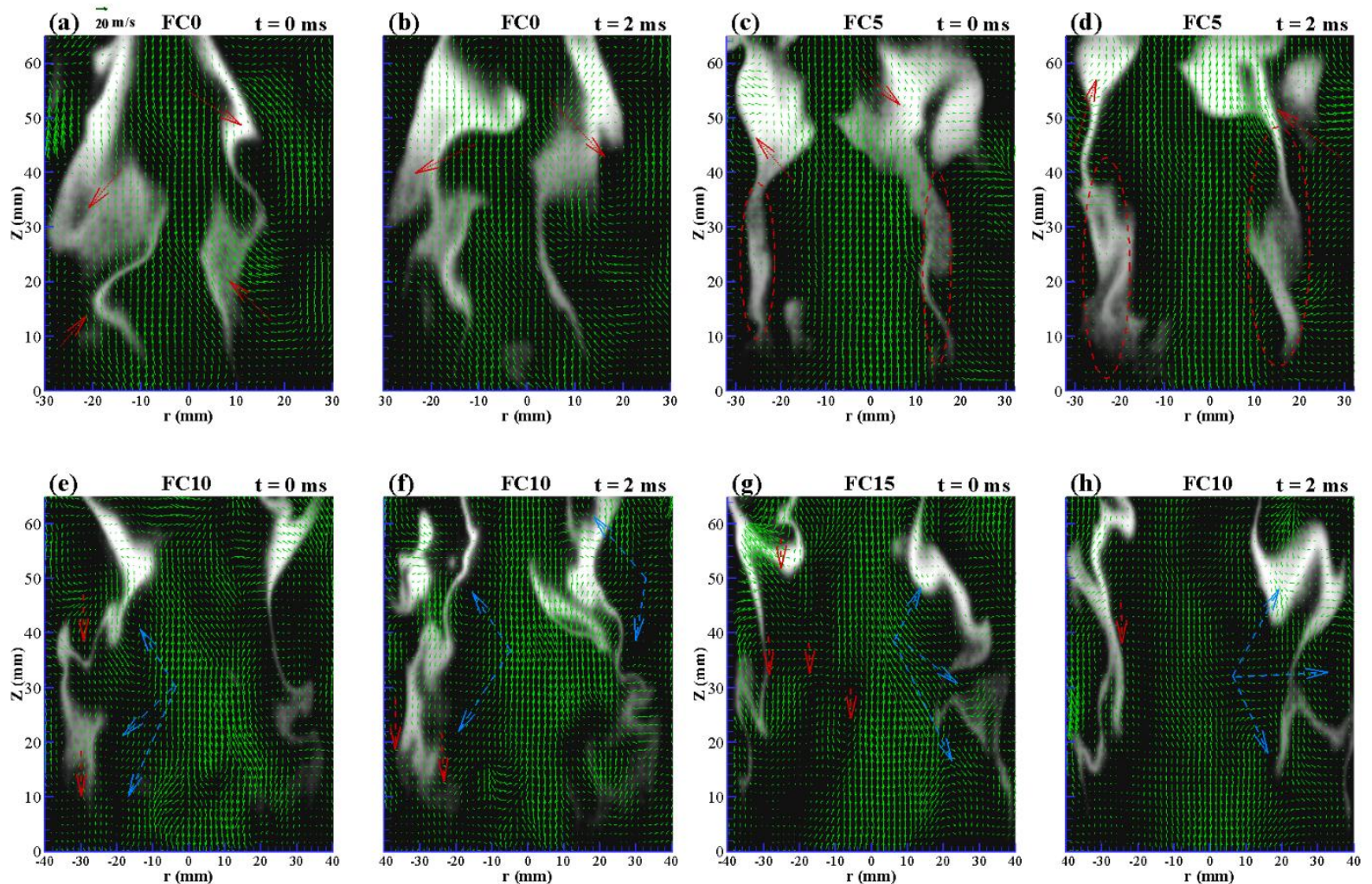

Figure 7. Instantaneous simultaneous velocity vectors from PIV and OH-PLIF image: (a-b) flame Fc0, (c-d) flame Fc5, (e-f) flame Fc10, and (g-h) flame Fc15.

This can be seen in the developed $\mathrm{OH}$ layer of flame Fc15, indicated by red arrows. This is clearer by studying the OH/SPIV images shown in Figs. 7e-7f for flame Fc10, which shows the rolling of the two sides of the flame towards the incoming fresh gases (shown by red arrows). However due to the dominant vortical structure at the shear layer, there is a mutual interaction between the downstream and upstream vortices, shown by the below arrows. Further increase of the coflow velocity to $15 \mathrm{~m} / \mathrm{s}$, does not show a significant difference in global flame structure to that of flame Fc10, as indicated in Fig. 6c and Fig. 6d. However, the bigger size of the annular 
formed vortex around the central jet leads to more mutual interaction between the jet and the coflow. The large vortex engulfs more (see the streamlines plot in Fig. 3d) of the fresh mixture towards the recirculated hot gases from further downstream distances. As indicated in Figs. 7g$7 \mathrm{~h}$, the multiple interactions between the different vortices along the outer shear layers helps in stabilizing the flame (shown by blue arrows).

To investigate the effect of the coflow on the strain rate field, the average maximum principal strain rates field in flames $\mathrm{Fc} 0$ and $\mathrm{Fc} 15$ together with the radial profiles of the strain rates at axial distance, $\mathrm{Z}=25 \mathrm{~mm}$ are shown in Fig. 8. The coflow has a significant effect on the strain rates distribution as shown in Figs. 8a-8b, the existence of the coflow decreases the strain rates of main jet. As illustrated by the strain rate radial profiles at $Z=25 \mathrm{~mm}$ in Fig. $8 \mathrm{c}$, the central jet of flame Fc0 peaks a strain rate of $440(1 / \mathrm{s})$ and it decreases to a peak of $350(1 / \mathrm{s})$ in flame Fc15. One can notice that the coflow confines the main jet with an annular region of relative low strain where the flame anchored at the inner radius of the diverging nozzle, while the maximum strain is located at the coflow stream. On the contrary, in Fc0 as shown in Figs. 7a-7b, the flames is located around the jet shear layers where the strain rates is still relatively high as indicated in Fig. 8a. This implies that the existence of the coflow around the conical nozzle significantly enhances the flame stabilization. 

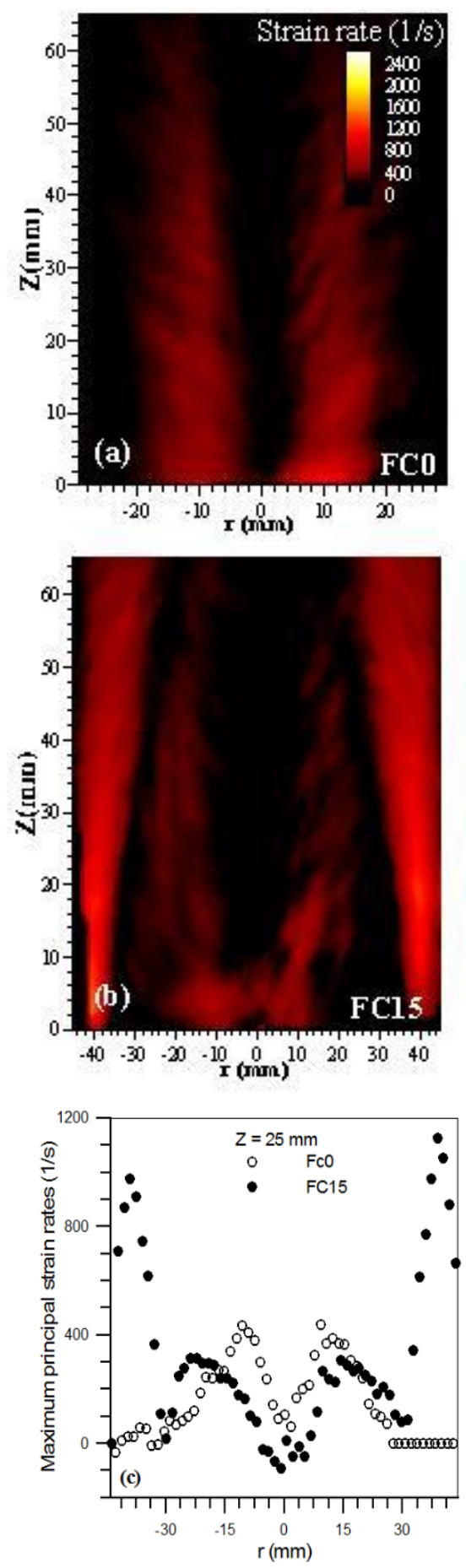

Figure 8. Average maximum principal strain rates: (a) for flames $\mathrm{Fc} 0$, (b) for flame $\mathrm{Fc} 15$, and (c) the radial profiles of the principal strain rates at $\mathrm{Z}=25 \mathrm{~mm}$ in flames $\mathrm{Fc} 0$ and $\mathrm{Fc} 15$. 


\section{Conclusions}

The effects of coflow on the flame stability and structure of partial premixed propane jet flames stabilized in a concentric flow conical nozzle burner with air coflow were studied experimentally. The effects of the jet equivalence ratio, Reynolds number, level of inhomogeneity and air coflow velocity on the stability characteristics of propane flames are investigated. In addition, the flow field characteristics and the flame structure based on $\mathrm{OH}$ radical field measurements are presented and discussed. The results show that the flames are highly stabilized at a certain level of inhomogeneity and range of mixture fraction fluctuations for all operating conditions of Re, $\Phi$ and air coflow velocity. This range corresponds to $40 \%$ of the flammability limits range of propane. The air coflow creates a recirculation zone at the tip of the conical nozzle and this improves the flame stability. High coflow velocity leads to a stronger recirculation zone and improves the flame stability. The higher the coflow velocity, the larger the mutual interaction between the central jet and the coflow. Interpretation of the individual simultaneous OH/SPIV measurements sequences yielded physical insight into various relevant combustion dynamics phenomena and underling flow physics which improves the flame stability with coflow velocity. For the flame with no air coflow, the flame was seen to reside primarily close to the shear layer which is dominated by vertical structures. This results in significant wrinkling and corrugation of the reaction zone. In contrast, for the cases with coflow, the flame is pushed outward where it resides in the region of low axial velocity, and the strain rate is correspondingly relatively low. At higher air coflow velocity, the large momentum associated with the reversed flow causes the reaction zone to conform to the RZ and resides in the region of low axial velocity along the interface between incoming unburned gas and the high temperature 
coming from the downstream gases through the RZ. Thus, this serves as an ignition source for the fresh mixture and leads to anchor the flame to the conical nozzle tip.

We may conclude that stabilization of the flames in the presence of the coflow is controlled by the mutual interactions between the central jet and the coflow through the resulting RZ from and the degree of inhomogeneity of the central jet mixture.

\section{Acknowledgments}

The present work was conducted at clean combustion research center, CCRC, King Abdullah University for Science and Technology, KAUST, in cooperation with Cairo and Helwan Universities, Cairo, Egypt.

\section{References}

[1] A. Masri, Partial premixing and stratification in turbulent flames, Proceedings of the Combustion Institute 35 (2015) 1115-1136.

[2] M.S. Mansour, Classification of the Mixing Field of Partially Premixed Flames Using Regime Diagram, Combustion Science and Technology 188 (2016) 667-683.

[3] M. Mansour, R. Bilger, S. Stårner, A reverse flow reactor for turbulence/chemistry interaction studies, Combustion science and technology 65 (1989) 83-101.

[4] M.S. Mansour, A concentric flow conical nozzle burner for highly stabilized partially premixed flames, Combustion science and technology 152 (2000) 115-145.

[5] T.-W. Lee, M. Fenton, R. Shankland, Effects of variable partial premixing on turbulent jet flame structure, Combustion and flame 109 (1997) 536-548.

[6] S. Meares, A.R. Masri, A modified piloted burner for stabilizing turbulent flames of inhomogeneous mixtures, Combustion and Flame 161 (2014) 484-495.

[7] C.X. Thong, P.A. Kalt, B.B. Dally, C.H. Birzer, Flow dynamics of multi-lateral jets injection into a round pipe flow, Experiments in Fluids 56 (2015) 15.

[8] C.X. Thong, B.B. Dally, C.H. Birzer, P.A. Kalt, E.R. Hassan, An experimental study on the near flow field of a round jet affected by upstream multi-lateral side-jet, Experimental Thermal and Fluid Science 82 (2017) 198-211.

[9] C. X. Thong, B.B.Dally, P.R. Medwell, C.H. Birzer, Effect of multilateral jet mixing on stability and structure of turbulent non-premixed flames, Flow Turbulence and Combustion,100 (2018) 225-247.

[10] T. Wada, M. Mizomoto, T. Yokomori, N. Peters, Extinction of methane/air counterflow partially premixed flames, Proceedings of the Combustion Institute 32 (2009) 1075-1082.

[11] J.-W. Park, C.B. Oh, Flame structure and global flame response to the equivalence ratios of interacting partially premixed methane and hydrogen flames, international journal of hydrogen energy 37 (2012) 7877-7888.

[12] F. El-Mahallawy, A. Abdelhafez, M.S. Mansour, Mixing and nozzle geometry effects on flame structure and stability, Combustion science and technology 179 (2007) 249-263.

[13] S.A. Meares, Turbulent piloted jet flames with compositionally inhomogeneous inlets, (2014). 
[14] S. Meares, V. Prasad, G. Magnotti, R. Barlow, A. Masri, Stabilization of piloted turbulent flames with inhomogeneous inlets, Proceedings of the Combustion Institute 35 (2015) 1477-1484.

[15] A.M. Elbaz, M. Zayed, M. Samy, W.L. Roberts, M.S. Mansour, The flow field structure of highly stabilized partially premixed flames in a concentric flow conical nozzle burner with coflow, Experimental Thermal and Fluid Science 73 (2016) 2-9.

[16] M.S. Mansour, A. Elbaz, M. Samy, The stabilization mechanism of highly stabilized partially premixed flames in a concentric flow conical nozzle burner, Experimental Thermal and Fluid Science 43 (2012) 55-62.

[17] M.S. Mansour, The flow field structure at the base of lifted turbulent partially premixed jet flames, Experimental thermal and fluid science 28 (2004) 771-779.

[18] B. Li, E. Baudoin, R. Yu, Z. Sun, Z. Li, X.-S. Bai, M. Alden, M. Mansour, "Experimental and numerical study of a conical turbulent partially premixed flame", Proceedings of the Combustion Institute 32 (2009) 1811-1818.

[19] B. Yan, B. Li, E. Baudoin, C. Liu, Z. Sun, Z. Li, X.-S. Bai, M. Aldén, G. Chen, M. Mansour, Structures and stabilization of low calorific value gas turbulent partially premixed flames in a conical burner, Experimental thermal and fluid science 34 (2010) 412-419.

[20] E. Baudoin, X.-S. Bai, B. Yan, C. Liu, R. Yu, A. Lantz, S.M. Hosseini, B. Li, A. Elbaz, M. Sami, Effect of partial premixing on stabilization and local extinction of turbulent methane/air flames, Flow, turbulence and combustion 90 (2013) 269-284.

[21] M.S. Mansour, A.M. Elbaz, W.L. Roberts, M.S. Senosy, M.F. Zayed, M. Juddoo, A.R. Masri, Effect of the mixing fields on the stability and structure of turbulent partially premixed flames in a concentric flow conical nozzle burner, Combustion and Flame 175 (2017) 180-200.

[22] R. Barlow, S. Meares, G. Magnotti, H. Cutcher, A. Masri, Local extinction and near-field structure in piloted turbulent $\mathrm{CH}$ 4/air jet flames with inhomogeneous inlets, Combustion and Flame 162 (2015) 3516-3540.

[23] A.M. Elbaz, Early structure of LPG partially premixed conically stabilized flames, Experimental Thermal and Fluid Science 44 (2013) 583-591.

[24] A.M. Elbaz, W.L. Roberts, Experimental characterization of methane inverse diffusion flame, Combustion Science and Technology 186 (2014) 1249-1272.

[25] A.M. Elbaz, W.L. Roberts, Experimental study of the inverse diffusion flame using high repetition rate OH/acetone PLIF and PIV, Fuel 165 (2016) 447-461.

[26] N. Peters, Turbulent combustion, Cambridge university press 2000.

[27] M.G. Zabetakis, Flammability characteristics of combustible gases and vapors, DTIC Document, 1965. 


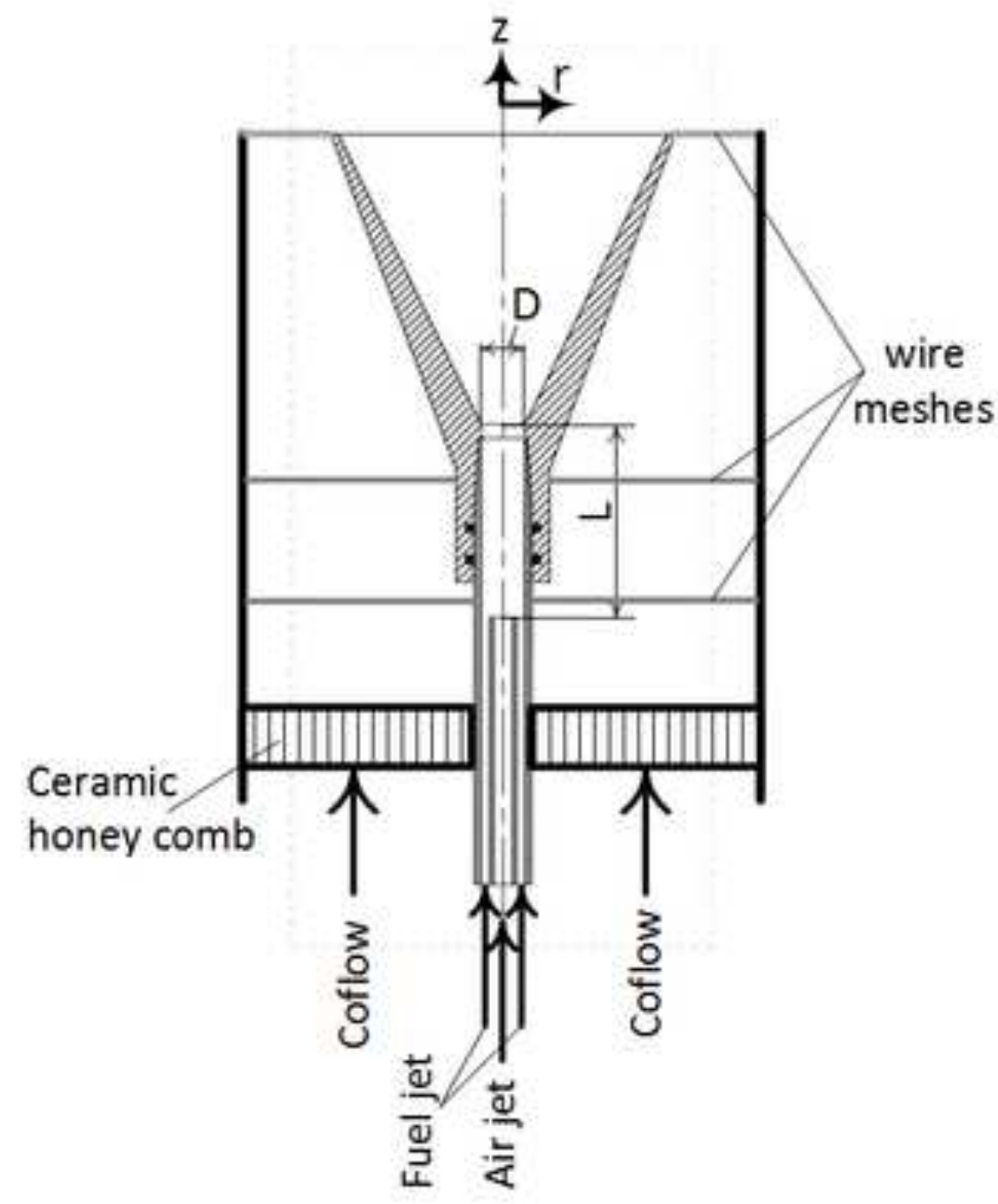

(a)

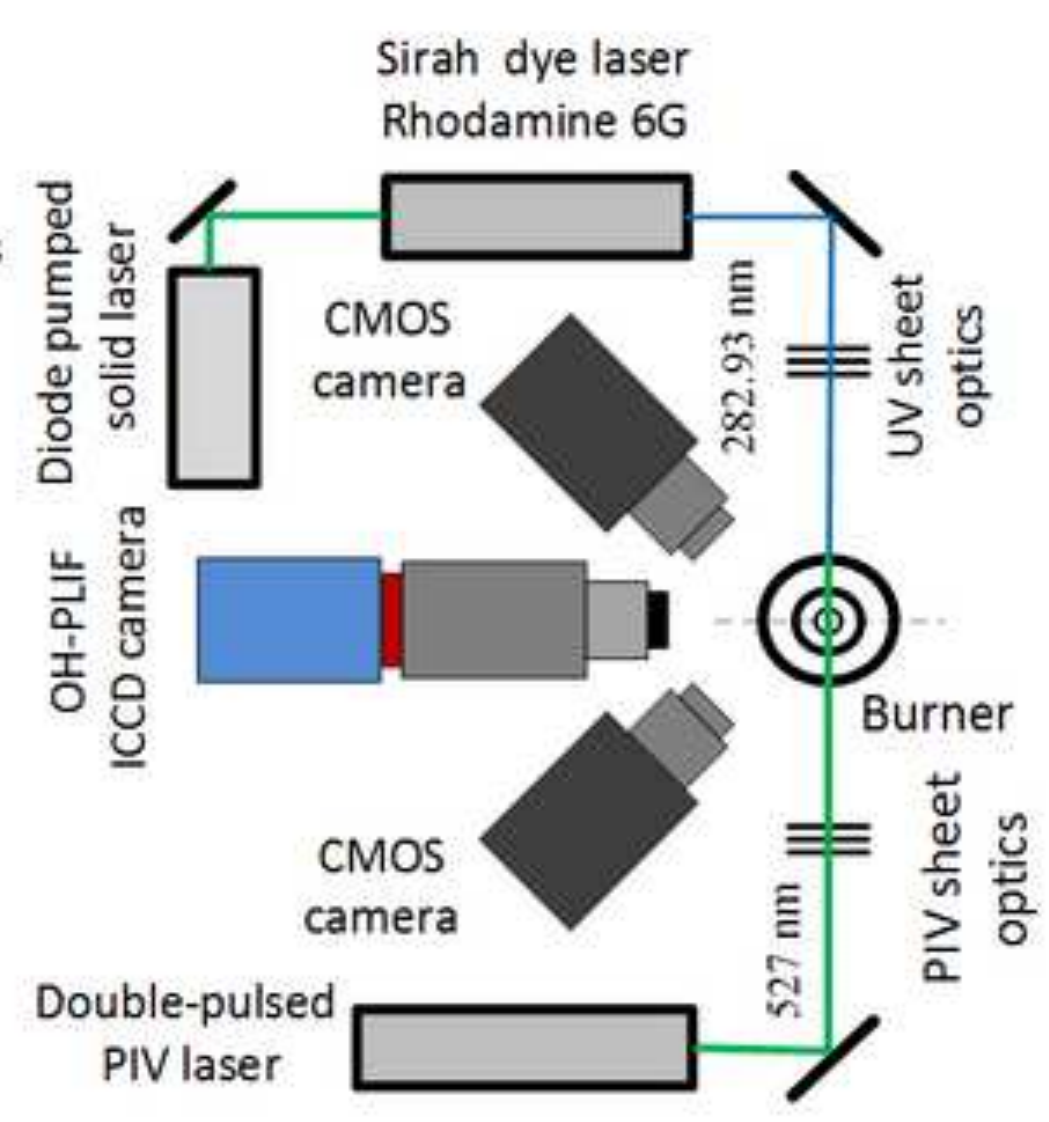

(b) 


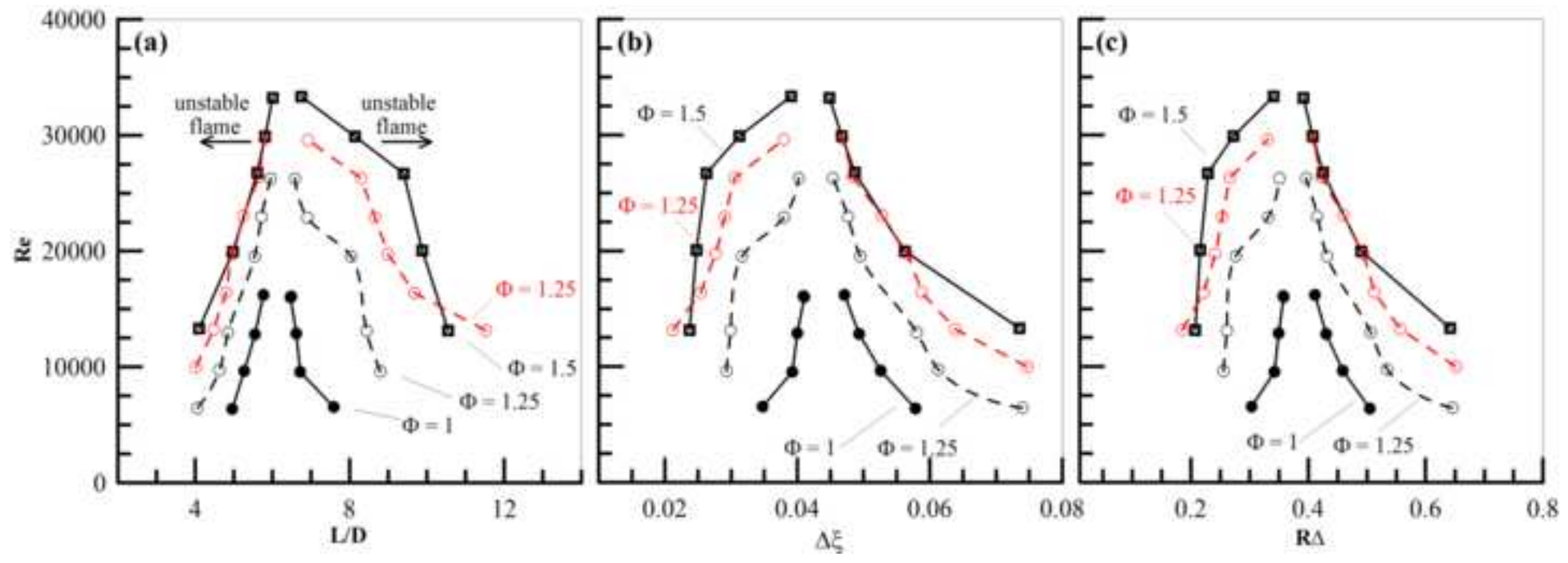



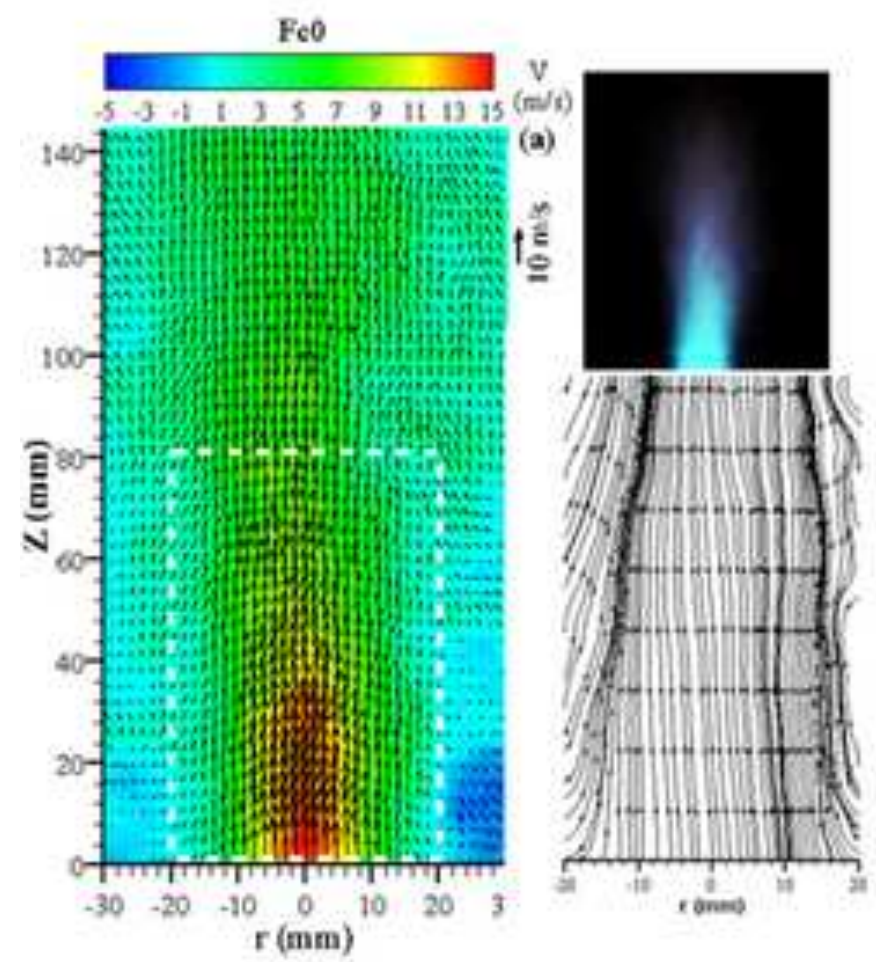

Felo

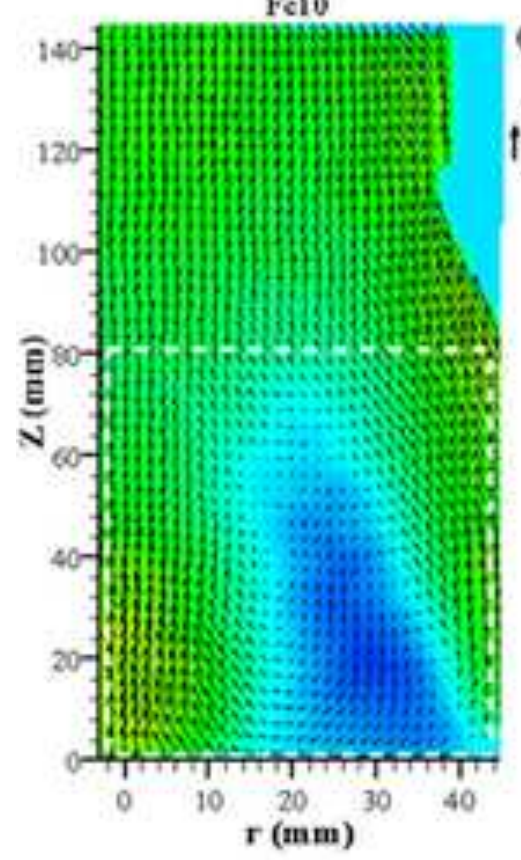

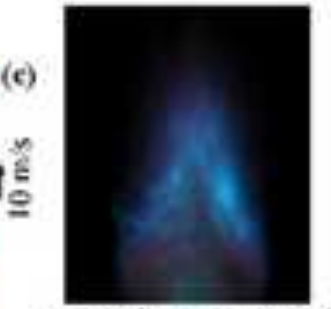

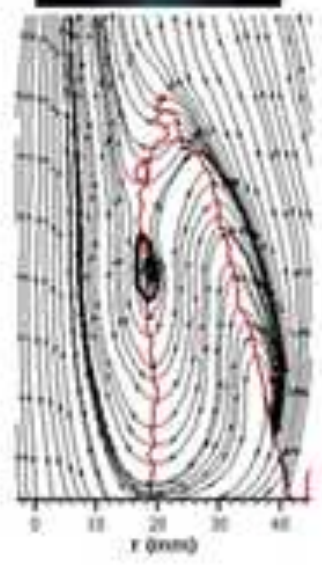

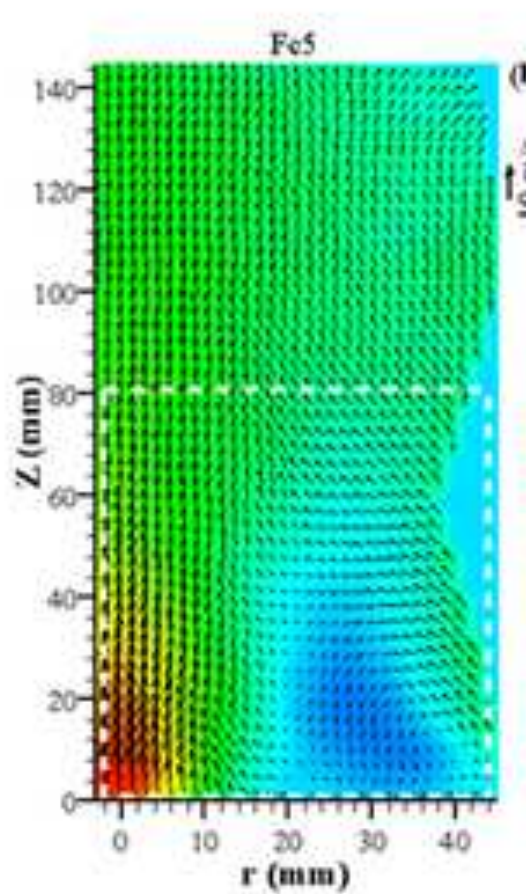
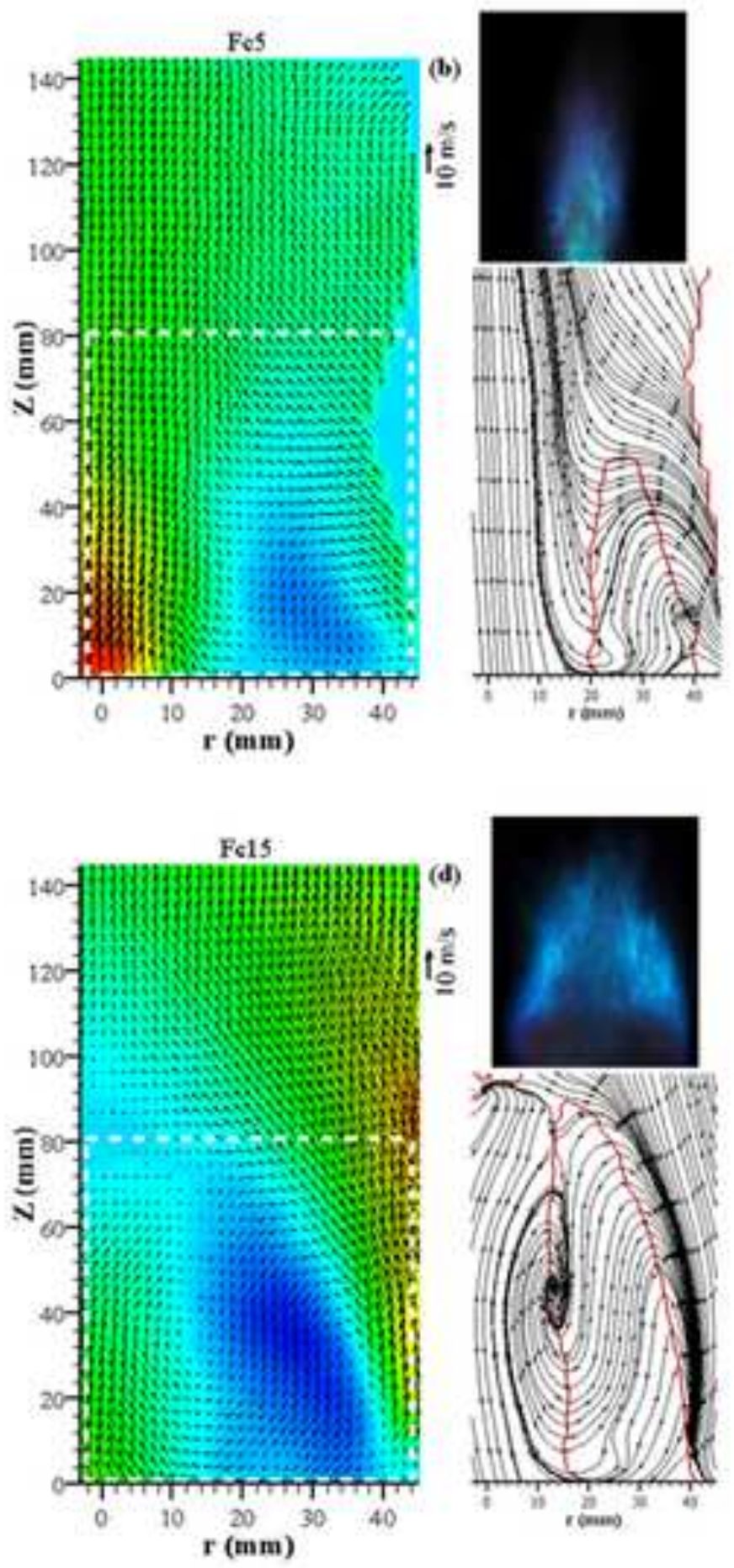

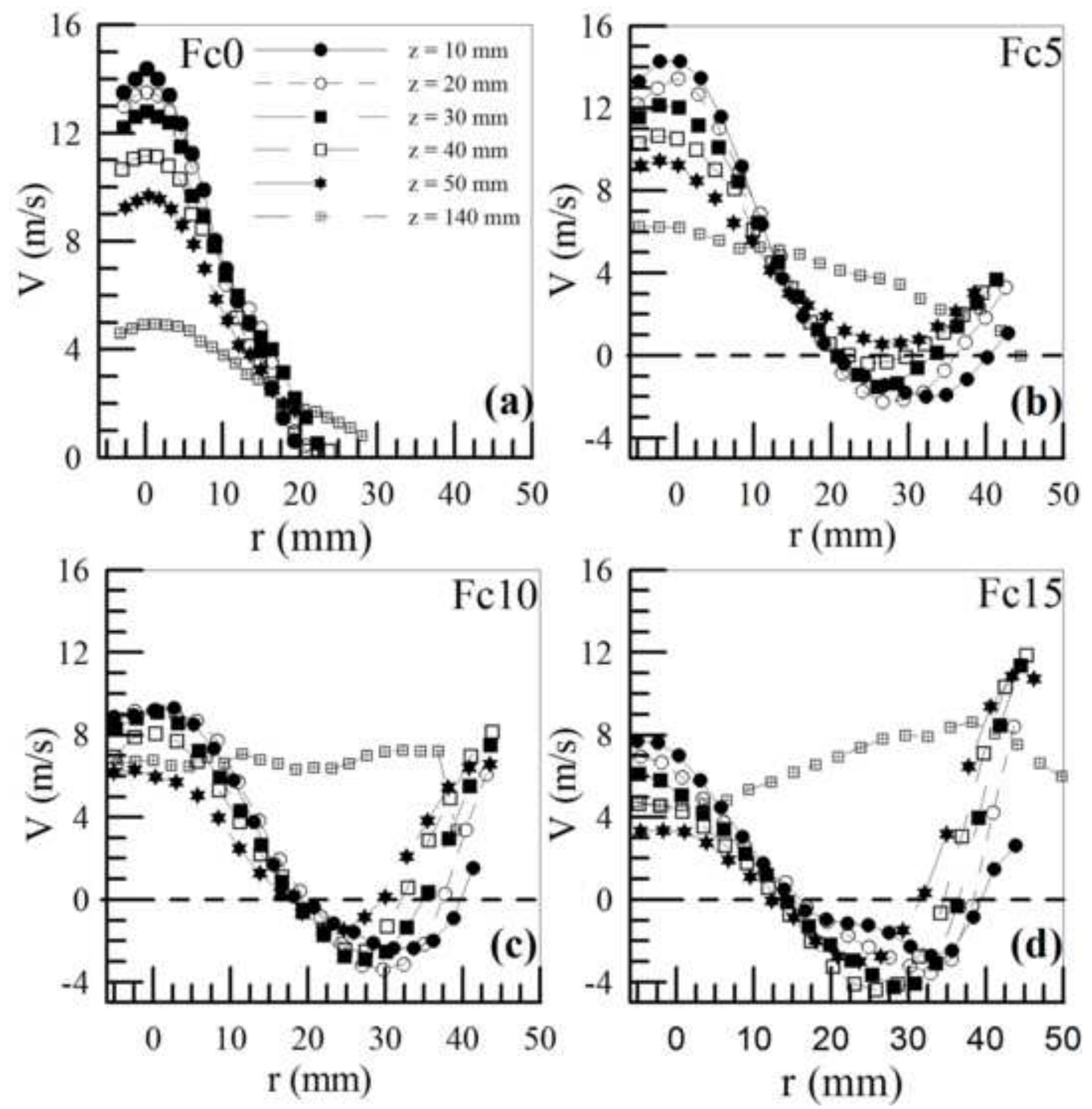


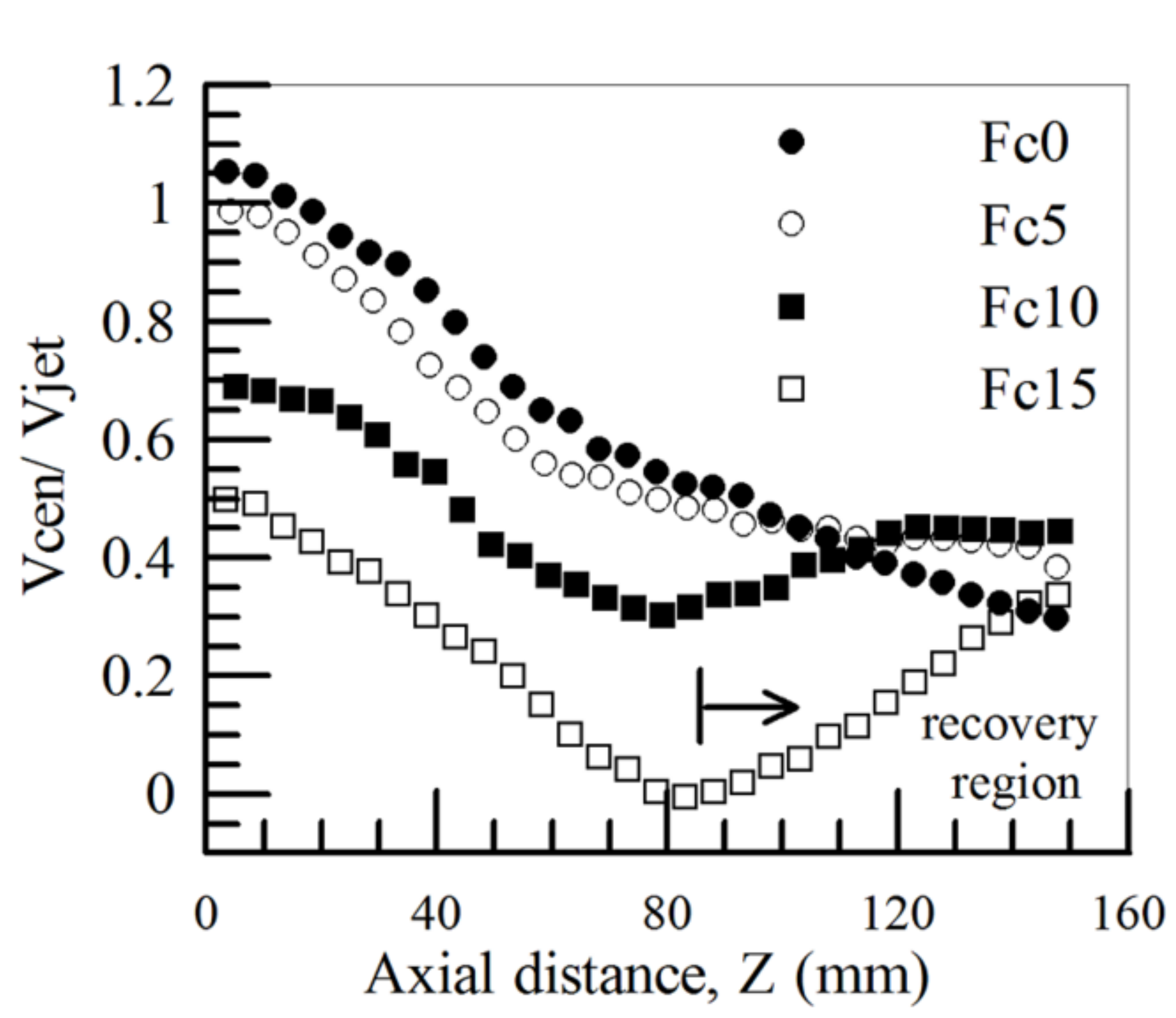



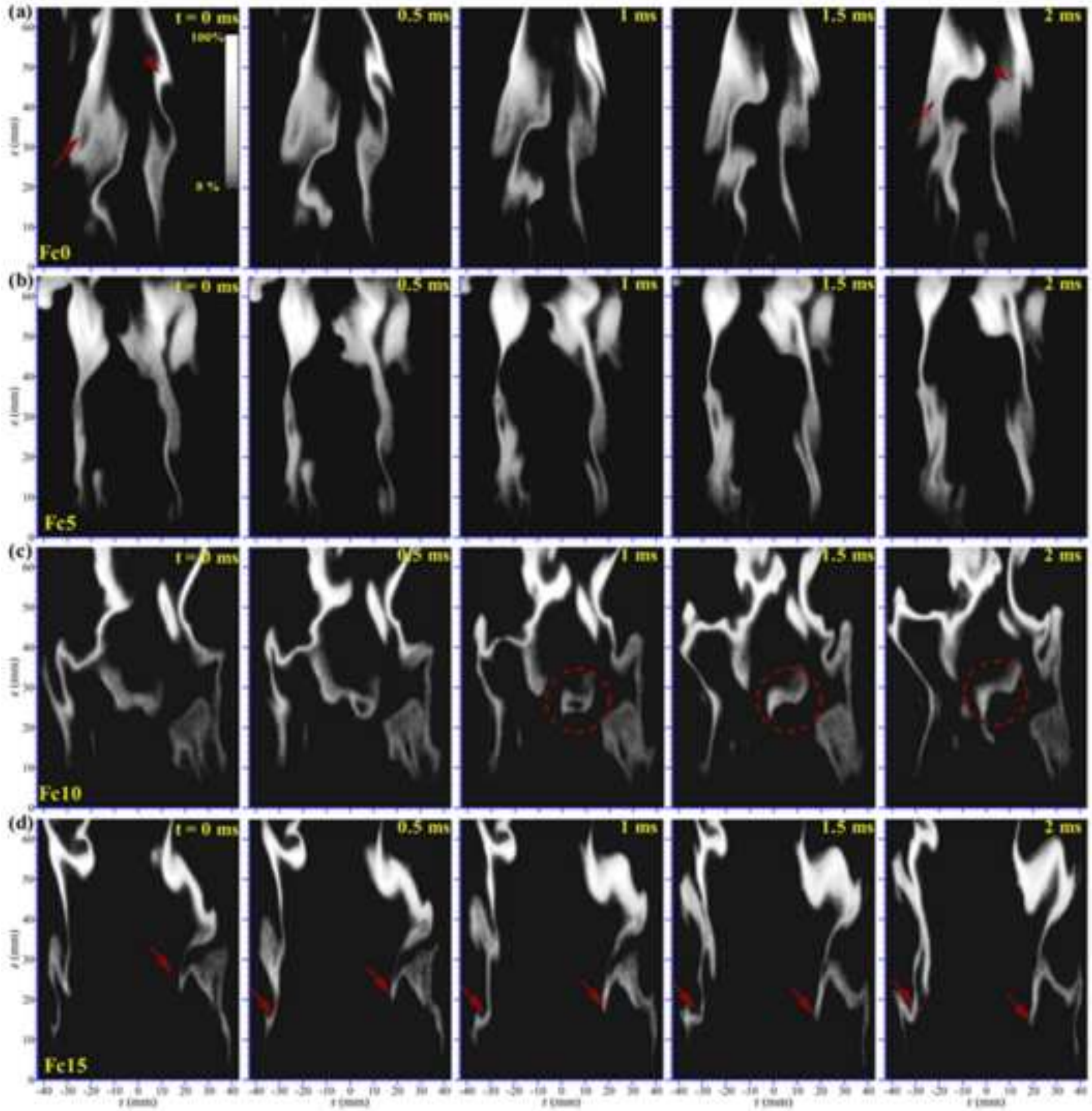

I unat? 

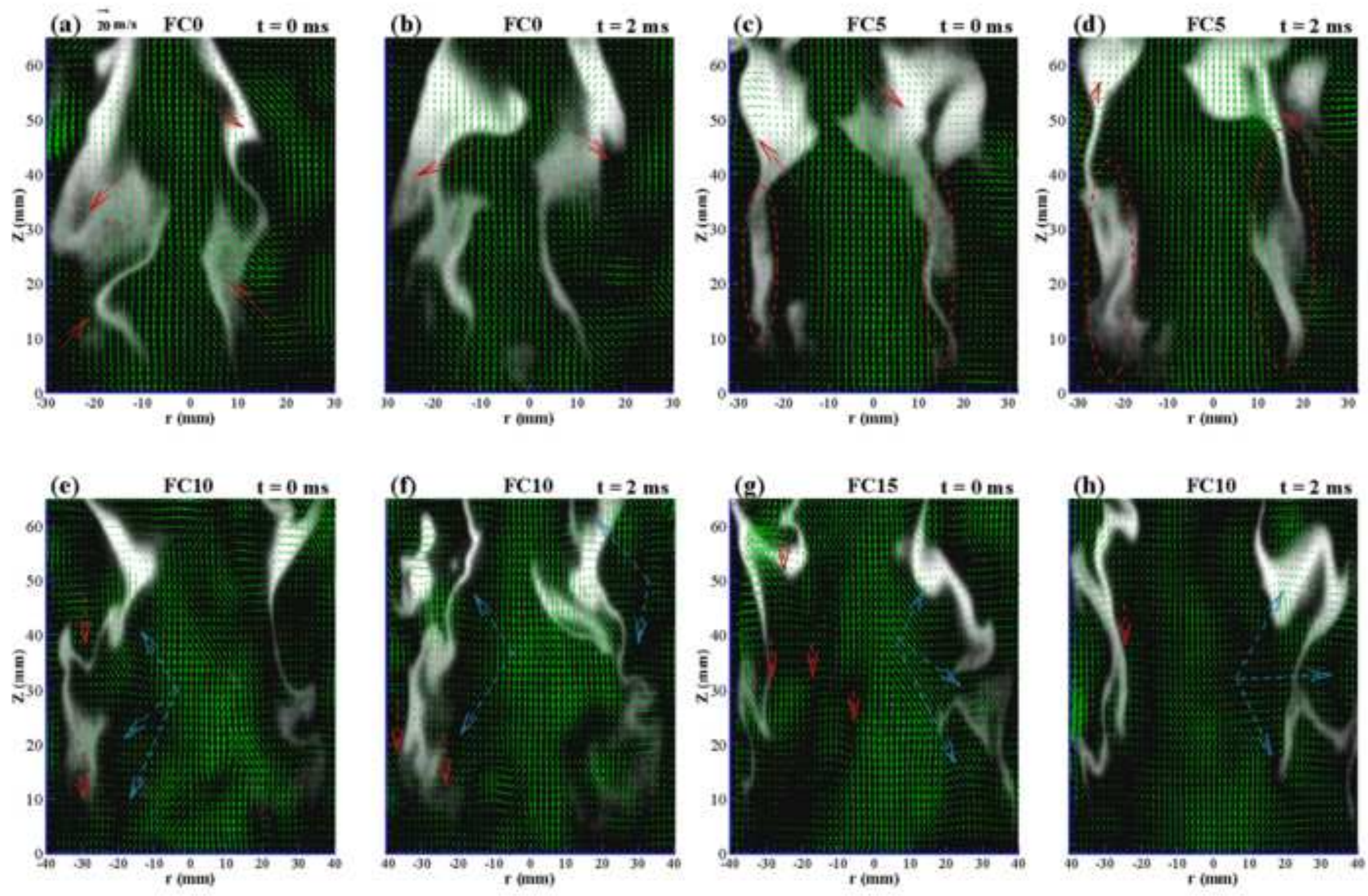
December 20, 2017

Professor Nevin Selcuk

Department of Chemical Engineering

Middle East Technical University

06531 Ankara Turkey

Subject: Experimental Thermal Fluid Science Journal, ETFS

Manuscript: HIGHLY STABILIZED PARTIALLY PREMIXED FLAMES OF PROPANE IN A CONCENTRICFLOW CONICAL NOZZLE BURNER WITH COFLOW

Authors: A.M. Elbaz, M.S. Senosy, M.F. Zayed, W.L. Roberts, and M.S. Mansour

\section{Dear Prof. Nevin:}

Thank you for accepting our paper to be published in ETFS. We have revised the manuscript in response to reviewer's comments as well as the editor's comments. In the attached pages, we indicate the changes to the paper in response to the reviewer comments in black writing. The reviewers' comments are given in italic red writing and our response is directly following.

I appreciate your efforts with regard to the manuscript.

I hope to see you again next MCS.

Best Regards,

Ayman M. Elbaz

Research Scientist, PhD.

Clean Combustion Research Center, KAUST

Building 5, Level four, 4216-Ws18

Cell:0544701524

Office: 8084625 


\section{Reviewer 1 comments:}

The paper describes the flame stabilization properties of a burner where unmixedness at the flame can be controlled by shifting axial fuel injection with respect to air injection. Aerodynamic stabilization of the flame is obtained via injection of coflowing air which produces reverse velocity inside the cone burner. This a very valuable set of experimental data with large variation of controlling parameters. The analysis of these data however is too much at qualitative level, limited to just a phenomenological description of the physical mechanisms driving flame stabilization. The author should consider expanding their analysis in terms of more quantitative interpretation of the data for example relation with the recirculated hot gas volume or strain rate at the flame anchoring locations. Few more questions:

- What is the exact meaning of $\xi$ describing fuel air mixing? Fuel mixture fraction?

\section{Authors' response:}

- We would to thank the reviewer for their valuable suggestions. We expanded the analysis of our results by including the strain rate plots for the region where the flame is anchored for two flames, one with and one without air coflow. Discussing results of these strain rates added more insight to the effect of the coflow in enhancing flame stabilization and the suggested flame stabilization mechanism of partial premixed flame. Consequently, we added a new figure, Fig. 8 in the revised version, illustrating the strain rate and one short paragraph of discussion of the strain rate at end of section 3 .

- The $\xi$ is the mixture fraction (a conserved scalar), which is defined as the mass percentage of the fuel elements in a gaseous mixture, i.e., $\xi=\sum y_{F i}, y_{F i}$ are the fuel elements' mass fractions. A new statement to define the fuel mixture fraction is included in the revised manuscript version and a new reference for the mixture fraction definition.

\section{Editor comments}

Please make the following corrections:

1. Name of the second author (M.S. Senosy) in the cover letter is wrong and has to be corrected.

- It is corrected in the cover letter.

2. Define abbreviations that are not standard in this field in a footnote to be placed on the first page of the article. Abbreviations, namely SPIV and OH-PLIF, that are 
unavoidable in the abstract must be defined at their first mention there, as well as in the footnote.

- This is corrected by including the definition of the abbreviations SPIV and OHPLIF with their first mention in the abstract.

3. While submitting the paper online, you need to upload each figure seperately in the evise system. These figures must be either TIFF or JPEG with the following minimum resolutions:

- TIFF (or JPG): Color or grayscale photographs (halftones): always use a minimum of 300 dpi.

- TIFF (or JPG): Bitmapped line drawings: use a minimum of $1000 \mathrm{dpi}$.

- TIFF (or JPG): Combinations bitmapped line/half-tone (color or grayscale): a minimum of 500 dpi

Your figures in the manuscript file are formatted as BITMAP which is not allowed. This is why Evise system gave you the error message in the first submission. Increasing the resolution in BITMAP format is not enough. You have to prepare each figure as TIFF / $J P G$ format as shown above and upload each figure separately while you are submitting online.

- We corrected this and prepared separate files for each figure while keeping the figures in JPG and tiff format. 